\title{
A flexible method to create wave file features
}

\author{
Ghazi M. J. Qaryouti, Tariq M. Younes
}

Department of Mechatronics Engineering, Faculty of Engineering Technology, Al-Balqa Applied University, Jordan

\begin{tabular}{l} 
Article Info \\
\hline Article history: \\
Received Apr 10, 2020 \\
Revised Jul 27, 2020 \\
Accepted Oct 27, 2020 \\
\hline
\end{tabular}

\section{Keywords:}

Clustering

Crest factor

Dynamic range

Histogram

K-mean clustering

\begin{abstract}
Digital audio signal is one of the most important data type at present, it is used in various vital applications, such as human knowledge, security and banking applications, most applications require signal identification and recognition, and to increase the efficiency of these applications we must seek a method to represent the audio file by a small set of values called a features vector. In this paper research we will introduce an enhanced method of features extraction based on k-mean clustering. The method will be tested and implemented to show how the proposed method can reduce the efforts of voice identification, and can minimize the recognition time a set of voice extracted features must be used instead of using the voice wave file.
\end{abstract}

This is an open access article under the CC BY-SA license.

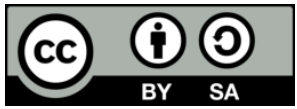

\section{Corresponding Author:}

Ghazi M. J. Qaryouti

Department of Mechatronics Engineering

Faculty of Engineering Technology

Al-Balqa, Applied University, Jordan

Email: ghazi_qaryouti@bau.edu.jo

\section{INTRODUCTION}

Digital audio signal is one of the most popular types of digital data utilized in a variety of bioengineering applications. Many of these applications depend on voice tags to distinguish different sounds and words and different people [1,2]. The analog audio signals is captured using special units, where this signals is passed over the analog to digital converter. As shown in Figure 1, sampling, quantization and encoding analysis are carried out through this unit.

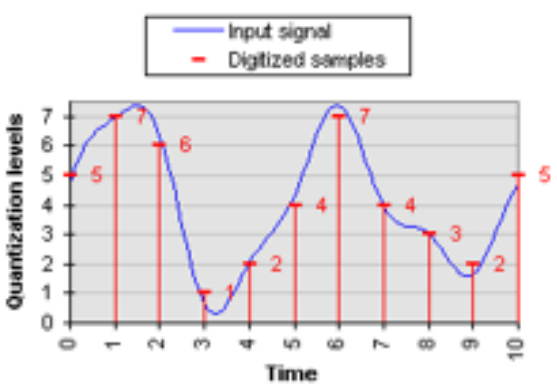

(a)



(b)

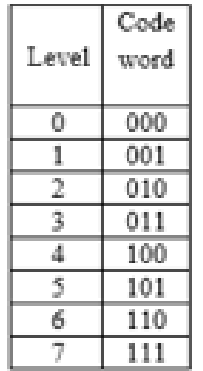

(c)

Figure 1. Analog to digital converting process: (a) Sampling, (b) quantization, (c) encoding analysis 
Digital audio files have large sizes [3,4], due to the multiplicity of audio samples taken in the specified period of time and due to the possibility of the audio file being mono or stereo [5-7]. Which is organized in one or two columns, which will increase the size of the file. Therefore, comparing audio files in the form of samples will take a long time $[8,9]$, as shown in Table 1.

Table 1. Matching time for different wave files

\begin{tabular}{ccccc}
\hline Wave file & Type & Channel size & $\begin{array}{c}\text { Total size } \\
\text { (bytes) }\end{array}$ & $\begin{array}{c}\text { Matching time } \\
\text { (Seconds) }\end{array}$ \\
\hline 1 & Stereo & 36787 & 294296 & 0.006 \\
2 & Stereo & 39730 & 317840 & 0.008 \\
3 & Stereo & 33844 & 270752 & 0.0076 \\
4 & Stereo & 17658 & 141264 & 0.005 \\
5 & Stereo & 41202 & 329616 & 0.0079 \\
6 & Stereo & 36787 & 294296 & 0.006 \\
7 & Stereo & 63274 & 506192 & 0.014 \\
8 & Stereo & 48049 & 384392 & 0.01 \\
9 & Stereo & 55916 & 447328 & 0.013 \\
10 & Stereo & 89760 & 718080 & 0.018 \\
Average & & 46300 & 370405 & 0.0097 \\
Cost of 1 sample & & & $9700 / 370405=0.0262$ microseconds/byte \\
\hline
\end{tabular}

Based on the foregoing, the importance of searching for a method to represent the audio file with a set of values that can be used as a depressor for the audio file becomes an urgent task [10-12]. Many researchers have developed a group of methods based on the use of sound suppressors by calculating some of the factors specific to the sound such as the crest factor [13], dynamic range [14-16], and using them as a lowering devices [17-19].

\section{WAVE FILE HISTOGRAM}

Data histogram [20-23] is an array of elements, each of which points to the repetition of one value in the data set [24-27]. Calculating the wave file histogram is an initial task of the proposed later in this paper method of features extraction. The wave file histogram can be calculated using the following MATLAB function. First we have to set the size of the histogram, here we use (1):

$$
n \text { Bins }=\text { round (datasetlength } / 15)
$$

Then we start arranging the wave file values, by calculation the repetition of each value, saving this repetition in the corresponding index of the histogram. Figure 2 shows the calculated histogram of a wave file example:

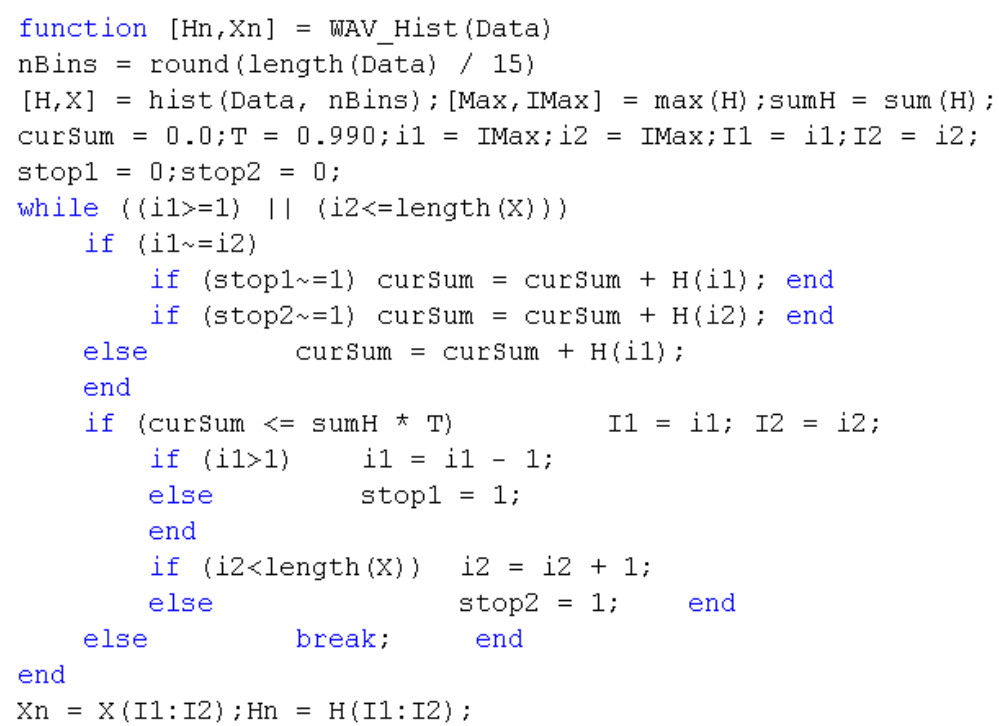






Figure 2. Wave file histogram (example)

\section{K-MEAN CLUSTERING}

Clustering means arranging data set values in groups (clusters), then the sums of values in each cluster, or the number of points in each cluster can be used as features for the data set [22]. K-mean clustering is implemented by applying a set of procedures which can be explained by the following example:

- Initialization:

Here we have to select the data set, number of clusters, and the centroid of each cluster:

Data set $=15,15,16,19,19,20,20,21,22,28,35,40,41,42,43,44,60,61,65$

Clusters $=2$;

$\mathrm{C} 1=16, \mathrm{C} 2=22$

- Perform the following tasks while centroid changing:

- Find distances to each cluster by taking the absolute value of the deference between the data item and the cluster centroid.

- Select the cluster to which the data item belongs by selecting the nearest cluster depending on the distance.

- Calculate the new centroid by averaging the data items belong to the cluster.

Table 2 and Table 3 shows the results of calculations:

Table 2. Calculation results of passes 1 and 2

\begin{tabular}{|c|c|c|c|c|c|c|}
\hline \multicolumn{4}{|c|}{ Pass 1 (Centroid 16 and 22) } & \multicolumn{3}{|c|}{ Pass 2} \\
\hline$x_{i}$ & $\begin{array}{l}\text { Distance } 1 \\
\left|x_{i}-c_{1}\right|\end{array}$ & $\begin{array}{c}\text { Distance } 2 \\
\left|x_{i}-c_{2}\right|\end{array}$ & $\begin{array}{c}\text { Nearest Cluster and } \\
\text { new Centroid } 15.33 \\
\text { and } 36.25 \\
15.33=(15+15++16) / 3\end{array}$ & $\begin{array}{l}\text { Distance } 1 \\
\left|x_{i}-c_{l}\right|\end{array}$ & $\begin{array}{c}\text { Distance } 2 \\
\left|x_{i}-c_{2}\right|\end{array}$ & $\begin{array}{l}\text { Nearest Cluster and new } \\
\text { Centroid 18.56and 45.9; }\end{array}$ \\
\hline 15 & 1 & 7 & 1 & 0.33 & 21.25 & 1 \\
\hline 15 & 1 & 7 & 1 & 0.33 & 21.25 & 1 \\
\hline 16 & 0 & 6 & 1 & 0.67 & 20.25 & 1 \\
\hline 19 & 3 & 3 & 2 & 3.67 & 17.25 & 1 \\
\hline 19 & 3 & 3 & 2 & 3.67 & 17.25 & 1 \\
\hline 20 & 4 & 2 & 2 & 4.67 & 16.25 & 1 \\
\hline 20 & 4 & 2 & 2 & 4.67 & 16.25 & 1 \\
\hline 21 & 5 & 1 & 2 & 5.67 & 15.25 & 1 \\
\hline 22 & 6 & 0 & 2 & 6.67 & 14.25 & 1 \\
\hline 28 & 12 & 6 & 2 & 12.67 & 8.25 & 2 \\
\hline 35 & 19 & 13 & 2 & 19.67 & 1.25 & 2 \\
\hline 40 & 24 & 18 & 2 & 24.67 & 3.75 & 2 \\
\hline 41 & 25 & 19 & 2 & 25.67 & 4.75 & 2 \\
\hline 42 & 26 & 20 & 2 & 26.67 & 5.75 & 2 \\
\hline 43 & 27 & 21 & 2 & 27.67 & 6.75 & 2 \\
\hline 44 & 28 & 22 & 2 & 28.67 & 7.75 & 2 \\
\hline 60 & 44 & 38 & 2 & 44.67 & 23.75 & 2 \\
\hline 61 & 45 & 39 & 2 & 45.67 & 24.75 & 2 \\
\hline 65 & 49 & 43 & 2 & 49.67 & 28.75 & 2 \\
\hline
\end{tabular}




\begin{tabular}{|c|c|c|c|c|c|c|}
\hline & & Pass 3 & & & Pass & \\
\hline$x_{i}$ & $\begin{array}{l}\text { Distance } 1 \\
|| x_{i}-c_{l} \mid\end{array}$ & $\begin{array}{c}\text { Distance } 2 \\
\left|x_{i}-c_{2}\right|\end{array}$ & $\begin{array}{c}\text { Nearest Cluster and } \\
\text { new Centroid 19.50and } \\
47.89\end{array}$ & $\begin{array}{l}\text { Distance } 1 \\
\left|x_{i}-c_{l}\right|\end{array}$ & $\begin{array}{l}\text { Distance } 2 \\
\left|x_{i}-c_{2}\right|\end{array}$ & $\begin{array}{l}\text { Nearest Cluster and new } \\
\text { Centroid } 19.50 \text { and } 47.89\end{array}$ \\
\hline 15 & 3.56 & 30.9 & 1 & 4.50 & 32.89 & 1 \\
\hline 15 & 3.56 & 30.9 & 1 & 4.50 & 32.89 & 1 \\
\hline 19 & 0.44 & 26.9 & 1 & 0.50 & 28.89 & 1 \\
\hline 20 & 1.44 & 25.9 & 1 & 0.50 & 27.89 & 1 \\
\hline 20 & 1.44 & 25.9 & 1 & 0.50 & 27.89 & 1 \\
\hline 21 & 2.44 & 24.9 & 1 & 1.50 & 26.89 & 1 \\
\hline 22 & 3.44 & 23.9 & 1 & 2.50 & 25.89 & 1 \\
\hline 42 & 23.44 & 3.9 & 2 & 22.50 & 5.89 & 2 \\
\hline 43 & 24.44 & 2.9 & 2 & 23.50 & 4.89 & 2 \\
\hline 44 & 25.44 & 1.9 & 2 & 24.50 & 3.89 & 2 \\
\hline 60 & 41.44 & 14.1 & 2 & 40.50 & 12.11 & 2 \\
\hline 61 & 42.44 & 15.1 & 2 & 41.50 & 13.11 & 2 \\
\hline 65 & 46.44 & 19.1 & 2 & 45.50 & 17.11 & 2 \\
\hline
\end{tabular}

\section{THE PROPOSED METHOD}

The proposed method of wave file features extraction is based on k-mean clustering and it can be implemented applying the following steps:

- Get the wave file.

- Calculate the wave file histogram to be used as an input data set for clustering.

- Initialization by selecting the number of clusters and a centroid for each cluster.

- Apply k-mean clustering.

- Save the clusters as a feature for the wave file.

\subsection{Implementation and experimental results}

A necessary MATLAB codes were written to create a features for a wav files using statistical method and k-mean method, below we will discuss the obtained experimental results.

\subsubsection{Statistical method}

\section{a. Experiment 1}

We took a sinusoidal signal and for deferent parameter values (amplitude, frequency and phase shifting) we calculate some statistical parameters, Table 4 shows the results of this experiment. From Table 4 we can see:

- Changing the signal parameters leads to changing the features set.

- Changing the features set means that the modified signal will be considered as a new signal thus will increase the memory space required to store the signals, and increase the required time for signal identification.

Table 4. Experiment 1 results

\begin{tabular}{lcccc}
\hline \multicolumn{1}{c}{ Signal } & \multicolumn{4}{c}{ Features set $(\mathrm{x}=-4 \mathrm{pi}: 0.001: 4 \mathrm{pi})$} \\
& Dynamic range $(\mathrm{db})$ & Crest factor $(\mathrm{db})$ & Mean & RMS value \\
\hline 1) $\mathrm{Y} 1=\sin (10 \mathrm{x}+5)$ & 80.7663 & 3.0098 & $-9.8742 \mathrm{e}-006$ & 0.70712 \\
2) $\mathrm{Y} 2=5 \sin (10 \mathrm{x}+5)$ & 68.0299 & 0.38655 & $-2.3672 \mathrm{e}-005$ & 0.95644 \\
3) $\mathrm{Y} 3=5 \sin (20 \mathrm{x}+5)$ & 76.3293 & 0.38656 & $-2.3711 \mathrm{e}-005$ & 0.95644 \\
4) $\mathrm{Y} 4=5 \sin (20 \mathrm{x}+15)$ & 76.3293 & 0.38655 & $-3.038 \mathrm{e}-006$ & 0.95644 \\
\hline
\end{tabular}

\section{b. Experiment 2}

Here we took the first version of the digital signal, and used it to create wave file with deferent sampling frequencies, Table 5 shows the results of this experiment. From the results shown in Table 5 we can see that the features set remain the same for the same wave file recorded with deferent sampling frequencies, which mean that all the wave file versions can be considered as one file with a stable set of features. 
Table 5. Experiment 2 results

\begin{tabular}{ccccc}
\hline Sampling frequency & \multicolumn{3}{c}{$\begin{array}{c}\text { Features } \\
\text { Y1=sin }(10 \mathrm{x}+5)\end{array}$} \\
& Dynamic range $(\mathrm{db})$ & Crest factor(db) & Mean & RMS value \\
\hline 1000 & 80.7663 & 3.0098 & $-9.8742 \mathrm{e}-006$ & 0.70712 \\
1500 & 80.7663 & 3.0098 & $-9.8742 \mathrm{e}-006$ & 0.70712 \\
2000 & 80.7663 & 3.0098 & $-9.8742 \mathrm{e}-006$ & 0.70712 \\
2500 & 80.7663 & 3.0098 & $-9.8742 \mathrm{e}-006$ & 0.70712 \\
3000 & 80.7663 & 3.0098 & $-9.8742 \mathrm{e}-006$ & 0.70712 \\
\hline
\end{tabular}

\section{c. Experiment 3}

Statistical method of wave file features extraction was implemented using various wave files, Table 6 shows the results of this experiment. From the results shown in Table 6 we can see that statistical method is good for wave file features extraction, each wave file has a unique features set, which can be used as a signature or a key to identify or recognize the wave file.

Table 6. Experiment 3 results

\begin{tabular}{ccccc}
\hline Wav file & \multicolumn{3}{c}{ Features set } \\
& Dynamic range $(\mathrm{db})$ & Crest factor(db) & Mean & RMS value \\
\hline bird & 32.0412 & 12.7755 & -0.0033595 & 0.071792 \\
bear_growl_y & 42.0761 & 11.737 & -0.039608 & 0.25689 \\
bird_caw1 & 42.0761 & 15.8556 & -0.0091737 & 0.15989 \\
bird_caw2 & 42.0761 & 14.6131 & -0.0093481 & 0.18448 \\
bird_chirp & 42.0761 & 13.5213 & -0.0092506 & 0.20918 \\
bird_chirping2 & 42.0761 & 14.0603 & -0.0036374 & 0.1966 \\
bison & 42.0761 & 11.1476 & -0.006455 & 0.27493 \\
cat_big_x & 42.0761 & 14.0567 & 0.0010605 & 0.19668 \\
cat_fight & 42.0761 & 10.935 & -0.043354 & 0.28174 \\
chicken & 41.1381 & 18.2011 & -0.0089245 & 0.10956 \\
cow1 & 42.0761 & 8.8379 & -0.0044406 & 0.35867 \\
dog_x & 42.0761 & 11.3235 & -0.0031504 & 0.26941 \\
\hline
\end{tabular}

\subsubsection{Proposed k-mean of features extraction}

a. Experiment 4

We took a sinusoidal signal and for deferent parameter values (amplitude, frequency and phase shifting), then we implemented k-mean method. Table 7 shows the results of this experiment.

Table 7. Experiment 4 results

\begin{tabular}{ccccc}
\hline Signal & \multicolumn{4}{c}{ Features(x=-4pi:0.001:4pi) } \\
& 213.1222 & 530.0000 & 795.0000 & 47.3315 \\
$\mathrm{Y} 1=\sin (10 \mathrm{x}+5)$ & 213.1222 & 530.0000 & 795.0000 & 47.3315 \\
$\mathrm{Y} 2=5 \sin (10 \mathrm{x}+5)$ & 213.1222 & 530.0000 & 795.0000 & 47.3315 \\
$\mathrm{Y} 3=5 \sin (20 \mathrm{x}+5)$ & 213.1222 & 530.0000 & 795.0000 & 47.3315 \\
$\mathrm{Y} 4=5 \sin (20 \mathrm{x}+15)$ & &
\end{tabular}

From Table 7 we can see:

- Changing the signal parameters does not lead to changing the features set.

- Changing the features set means that the modified signal will be considered as the new same signal thus this will not affect the memory space and the recognition time.

b. Experiment 5

Here we took the first version of the digital signal, and used it to create wave file with deferent sampling frequencies, Table 8 and Table 9 shows the results of this experiment. From the results shown in Table 8 and Table 9 we can see that the features set remain the same for the same wave file recorded with deferent sampling frequencies, which mean that all the wave file versions can be considered as one file with a stable set of features. 
Table 8. Experiment 5-1 results

\begin{tabular}{ccccc}
\hline Sampling frequency & \multicolumn{5}{c}{ Features set } \\
\hline 1000 & 1374 & 3348 & 5022 & 316.9 \\
1500 & 1374 & 3348 & 5022 & 316.9 \\
2000 & 1374 & 3348 & 5022 & 316.9 \\
2500 & 1374 & 3348 & 5022 & 316.9 \\
3000 & 1374 & 3348 & 5022 & 316.9 \\
\hline
\end{tabular}

Table 9. Experiment 5-2 results

\begin{tabular}{ccccc}
\hline Sampling frequency & \multicolumn{5}{c}{$\begin{array}{c}\text { Features set(*1.0e+003) } \\
\text { Bird wave file }\end{array}$} \\
\hline 11025 & 1.2416 & 3.3080 & 4.9620 & 0.7537 \\
12000 & 1.2416 & 3.3080 & 4.9620 & 0.7537 \\
10000 & 1.2416 & 3.3080 & 4.9620 & 0.7537 \\
8500 & 1.2416 & 3.3080 & 4.9620 & 0.7537 \\
6000 & 1.2416 & 3.3080 & 4.9620 & 0.7537 \\
& \multicolumn{5}{c}{} \\
15000 & 1.5593 & Bison wave file & \\
12000 & 1.5593 & 4.3880 & 6.5820 & 0.9327 \\
11025 & 1.5593 & 4.3880 & 6.5820 & 0.9327 \\
10000 & 1.5593 & 4.3880 & 6.5820 & 0.9327 \\
6000 & 1.5593 & 4.3880 & 6.5820 & 0.9327 \\
3000 & 1.5593 & 4.3880 & 6.5820 & 0.9327 \\
1000 & 1.5593 & 4.3880 & 6.5820 & 0.9327 \\
& \multicolumn{4}{c}{0.9327} \\
\hline
\end{tabular}

\section{c. Experiment 6}

K-mean method of wave file features extraction was implemented using various wave files, Table 10 shows the results of this experiment. From the results shown in Table 10 we can see that k-mean method is good for wave file features extraction, each wave file has a unique features set, which can be used as a signature or a key to identify or recognize the wave file.

Table 10. Experiment 6 results

\begin{tabular}{ccccc}
\hline Wav file & \multicolumn{4}{c}{ Features set(*1.0e+003) } \\
\hline bird & 1.2416 & 3.3080 & 4.9620 & 0.7537 \\
bear_growl_y & 1.7797 & 5.3800 & 8.0700 & 1.1491 \\
bird_caw1 & 1.1913 & 3.3080 & 4.9620 & 0.7665 \\
bird_caw2 & 1.5103 & 4.2960 & 6.4440 & 1.0081 \\
bird_chirp & 0.8042 & 2.2280 & 3.3420 & 0.5109 \\
bird_chirping2 & 0.8007 & 2.2312 & 3.3468 & 0.5261 \\
bison & 1.5593 & 4.3880 & 6.5820 & 0.9327 \\
cat_big_x & 1.5197 & 4.4880 & 6.7320 & 1.0143 \\
cat_fight & 1.1934 & 3.7468 & 5.6202 & 0.7035 \\
chicken & 0.3662 & 1.0000 & 1.5000 & 0.2420 \\
cow1 & 0.6767 & 1.8120 & 2.7180 & 0.3821 \\
dog_x & 0.7145 & 1.8352 & 2.7528 & 0.4367 \\
\hline
\end{tabular}

\section{d. Experiment 7}

Here we took the bird.wav wave file, and then we applied k-mean method of features extraction using the original file, amplified version of the file, amplified with addition version of the file, here the features remain the same without any changes as shown in Table 11.

Table 11. Experiment 7 results

\begin{tabular}{ccccc}
\hline Wave file & \multicolumn{5}{c}{$\begin{array}{c}\text { Features set(*1.0e+003) } \\
\text { Bird wave file }\end{array}$} \\
\hline X=bird & 1.2416 & 3.3080 & 4.9620 & 0.7537 \\
X=4X & 1.2416 & 3.3080 & 4.9620 & 0.7537 \\
X=X+5 & 1.2416 & 3.3080 & 4.9620 & 0.7537 \\
X=X-10 & 1.2416 & 3.3080 & 4.9620 & 0.7537 \\
X=2X+7 & 1.2416 & 3.3080 & 4.9620 & 0.7537 \\
\hline
\end{tabular}


As a conclusion of these experiments we can summarize the advantages of k-mean method of features extraction comparing with statistical method as shown in Table 12, and from this table we can see that k-mean method is more flexible especially when dealing with deferent versions of the original wave file.

Table 12. Comparisons between k-mean and statistical methods

\begin{tabular}{ccc}
\hline Wave file & K-mean method & Statistical method \\
\hline Original & Good & Good \\
Modified parameters & Good & Bad \\
Various sampling frequencies & Good & Good \\
Amplified & Good & Bad \\
Attenuated & Good & Bad \\
\hline
\end{tabular}

\section{CONCLUSION}

Experimental investigations of statistical and k-mean methods of wave file features extraction were proposed. Experimental results showed that k-mean method is more flexible by maintaining a stable set of features for the original wave file and other modified versions, which leads to minimizing the memory space and the required processing time needed for voice identification or recognition.

\section{REFERENCES}

[1] Brijesh N. S. and Jaymin K. B., "Comparative analysis and implementation of structured edge active contour," International Journal of Electrical and Computer Engineering (IJECE), vol. 10, no. 2, pp. 1842-1848. 2020.

[2] Barker J., et al., "The third 'CHiME' speech separation and recognition challenge: Dataset, task and baselines," IEEE Workshop on Automatic Speech Recognition and Understanding (ASRU), 2015, pp. 504-511.

[3] S. K. Dastoor, "Comparative Analysis of Steganographic Algorithms impacting the information in the Speech Signal for enhancing the Message Security in next Generation Mobile devices," World Congress on Information and Communication Technologies, pp. 279-284, 2011.

[4] Bin, et al., "Dynamic range estimation," IEEE Transactions on Computer-Aided Design of Integrated Circuits and Systems, vol. 25, no. 9, pp. 1618-1636, 2006.

[5] B. Wu, et al., "An analytical approach for dynamic range estimation," Proceedings of the $41^{\text {st }}$ annual Design Automation Conference, 2004, pp. 472-477.

[6] A. Marathe, P. Jain, and V. Vyas, "Iterative improved learning algorithm for petrographic image classification accuracy enhancement," International Journal of Electrical and Computer Engineering (IJECE), vol. 9, no. 1, pp. 289-296, 2019.

[7] F. Gouyon, et al., "Classifying percussive sounds: a matter of zero-crossing rate in Proceedings of the COST G-6," Conference on Digital Audio Effects (DAFX-00), 2000.

[8] D. D. Jaslene, "Feature Selection and Extraction of Audio," International Journal of Innovative Research in Science, Engineering and Technology, vol. 5, no. 3, pp. 3148-3155, 2016.

[9] Sanjivani S., et al., "An Overview of Technical Progress in Speech Recognition," International Journal of Advanced Research in Computer Science and Software Engineering, vol. 3, no. 3, pp. 488-497, 2013.

[10] M. I. Ouloul, et al., "An Efficient Face Recognition Using SIFT Descriptor in RGB-D Images," International Journal of Electrical and Computer Engineering (IJECE), vol. 5, no. 6, pp. 1227-1233, 2015.

[11] S. Narang and D. Gupta, "Speech Feature Extraction Techniques: A Review," International Journal of Computer Science and Mobile Computing, vol. 4, no. 3, pp. 107-114, 2015.

[12] M. J. Fadhil, R. A. Fayadh, and M. K. Wali, "Design and implementation a prototype system for fusion image by using SWT-PCA algorithm with FPGA technique," International Journal of Electrical and Computer Engineering (IJECE), vol. 10, no. 1, pp. 757-766, 2020.

[13] Rybach, et al., "The RWTH Aachen University Open Source Speech Recognition system," Tenth Annual Conference of the International Speech Communication Association, 2009.

[14] K. Matrouk, Ziad Alqadi, et al., "Speech Fingerprint to Identify Isolated Word-Person," World Applied Sciences Journal, vol. 31, no. 10, pp. 1767-1771, 2014.

[15] S. Khawatreh, Ziad Alqadi et al., "A Novel Methodology to Extract Voice Signal Features," International Journal of Computer Applications, vol. 179, no. 9, pp. 40-43, 2018.

[16] E. Benmalek, et al., "Voice Assessments for Detecting Patients with Parkinson's Diseases in Different Stages," International Journal of Electrical and Computer Engineering (IJECE), vol. 8, no. 6, pp. 4265-4271, 2018.

[17] V. Jaiswal, V. Sharma, and S. Varma, "MMFO: modified moth flame optimization algorithm for region based RGB color image segmentation," International Journal of Electrical and Computer Engineering (IJECE), vol. 10, no. 1, pp, 196-201, 2020.

[18] F. P. George, et al., "Recognition of emotional states using EEG signals based on time-frequency analysis and SVM classifier," International Journal of Electrical and Computer Engineering (IJECE), vol. 9, no. 2, pp. 1012-1020, 2019.

[19] Majed O. Al-Dwairi, et al, "A new method for voice signal features creation," International Journal of Electrical and Computer Engineering (IJECE), vol. 9, no. 5, pp. 4092-4098, 2019. 
[20] Ayman Al-Rawashdeh, Ziad Al-Qadi, "Using wave equation to extract digital signal features," Engineering, Technology \& Applied Science Research, vol. 8, no. 4, pp. 1356-1359, 2018.

[21] J Al Azzeh, Z Alqadi, and Qazem M Jabber, "Statistical Analysis of Methods Used to Enhanced color Image Histogram," XX International Scientific and Technical Conference, 2017, pp. 8-15.

[22] Tareq Khan, "Smart Microwave Oven with Image Classification and Temperature Recommendation Algorithm," International Journal of Electrical and Computer Engineering (IJECE), vol. 8, no. 6, pp. 4239-4252, 2018.

[23] Jihad Nadir, Ashraf Abu Ein, and Ziad Alqadi, "A Technique to Encrypt-decrypt Stereo Wave File," International Journal of Computer and Information Technology, vol. 5, no. 5, pp. 465-470, 2016.

[24] Ashraf Abu-Ein, Ziad AA Alqadi, Jihad Nader, "A technique of hiding secrete text in wave file," International Journal of Computer Applications, pp. 0975-8887, 2016.

[25] A. S. Jamil Al-Azzeh, et al., "Adaptation of matlab K-means clustering function to create color image features," International Journal of Research in Advanced Engineering and Technology, vol. 5, no. 2, pp. 10-18, 2019.

[26] M. Q. Shatnawi, M. Alrousan, S. Amareen, "A new approach for content-based image retrieval for medical applications using low-level image descriptors," International Journal of Electrical and Computer Engineering (IJECE), vol. 10, no. 4, pp. 4363-4371, 2020.

[27] Vijaya S. M. and Suresh K, "An efficient design approach of ROI based DWT using vedic and wallace tree multiplier on FPGA platform," International Journal of Electrical and Computer Engineering (IJECE), vol. 9, no. 4, pp. 2433-2442, 2019.

\section{BIOGRAPHY OF AUTHOR}

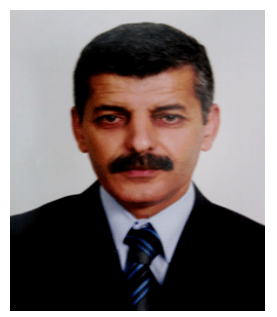

Ghazi M. J. Qaryouti received his B.Sc. in electrical Engineering from Damascus university in 1982, and M.S in Mechatronics Engineering from Al-Balqa Applied University Jordan in 2006, and Ph.D. degrees in Mechatronics Engineering from De Montfort University in Leicester, UK in 2015 His research interests are in Power Electronics and Electric Machine Drives, CNC Machine, 3D Printer, Energy Efficiency and Management, Renewable System, Image processing, and signals conditioning. Email : ghazi_qaryouti@bau.edu.jo

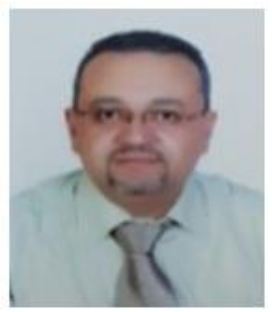

Tariq M. Younes was born in Irbid, Jordan, in 1974. He received the bachelor and Master Degrees in Biotechnical and medical apparatus and systems Engineering from Tver State Technical University (Russian Federation) in 1998, and Ph. D degree in Instrumentation and measurement from Moscow State University of Environmental Engineering in 2004. In 2004, he joined the Department of Computer Engineering, Faculty of Engineering Technology Al Balqa Applied University, as a part time Lecturer, and in 2005 he became a full-time lecturer at the same department. Since September 2007, he has been with the Department of Mechatronics Engineering at the same university, where he was an Assistant Professor, and he became an Associate Professor in 2012 